\title{
Ageing of Electric Vehicle Battery considering Mobility Needs for Urban Areas
}

\author{
Maurici Yagües-Gomà ${ }^{1}$, Pol Olivella-Rosell ${ }^{1}$, Roberto Villafafila-Robles ${ }^{1}$, Andreas Sumper ${ }^{1,2}$ \\ ${ }^{1}$ Centre d'Innovació Tecnològica en Convertidors Estàtics i Accionaments (CITCEA-UPC), Departament d'Enginyeria \\ Elèctrica, Universitat Politècnica de Catalunya-BarcelonaTech. EU d'Enginyeria Tècnica Industrial de Barcelona, Comte \\ d'Urgell, 187. 08036 Barcelona, Spain Tel: +34 934137432, e-mail: mauriciyagues@gmail.com, \\ pol.olivella@citcea.upc.edu, roberto.villafafila@citcea.upc.edu, sumper@ citcea.upc.edu \\ ${ }^{2}$ IREC Catalonia Institute for Energy Research, Jardins de les Dones de Negre 1, \\ 08930 Sant Adrià de Besós, Barcelona, Spain
}

\begin{abstract}
This work seeks to analyse battery wear in electric vehicles $(\mathrm{EV})$ based on daily usage and battery temperature. An agent-based model (ABM) was built, using Matlab® software, in order to evaluate users' behaviour and represent the output data. Travel input data is obtained from Barcelona's driving survey, and different models of battery electric vehicles (BEV), plug-in hybrid electric vehicles (PHEV), and electric motorcycles (EM) have been taken into consideration. Battery size characteristics and consumption are different for every model of vehicle, although only lithium ion (Li-ion) battery technology has been modelled and the same voltage profile has been used in all of them. The model successfully represents battery wear as a function of temperature and battery usage.
\end{abstract}

\section{Key words}

Electric vehicle, Li-ion battery, battery degradation, capacity fade, cycle life, driving patterns, agent-based modelling

\section{Introduction}

Even though vehicle electrification is growing globally, current EVs still lack competitiveness against its combustion counterparts, being price and driving range the main drawbacks. As of today, battery is the most expensive component of the vehicle, albeit its costs are expected to drop in the following years [1] [2]. This is not the only factor to take into account, as life span of the battery is an important subject when considering the overall cost of the vehicle. The main problem is the uncertainty of battery wear rates under different conditions, which makes it difficult to predict overall battery degradation.

Batteries used on EV face large variations in terms of temperature, frequency and depth of charge (DOD) and discharge cycles [3]. Knowing the correct degradation of EV batteries is important for correctly sizing them, in order to stand long term use and avoid range reduction affecting EV users. There is a need to develop reliable tools that can predict batteries state of health $(\mathrm{SOH})$ under real circumstances [3] [4].
This study evaluates battery capacity fade for a group of users with different mobility profiles and EV architectures. Battery wear rates are studied under different conditions of temperature and vehicle usage.

\section{Agent-based modelling}

The modelling technique used in this study is known as agent-based modelling. A similar approach to the one found in [5] has been followed. A set of agents has been defined, each one as an autonomous software entity, with different attributes. These determine the way the agent behaves in the given scenario, and how it interacts with the environment and other agents [6] [7]. The main reason this methodology is used, is the fact that it has been previously tested in mobility related applications [8], and it enables to test a wide range of different agents.

In this case, every agent will represent an EV owner, with its own driving profile for every day simulated and the same type of vehicle for all the period evaluated. Figure 1 shows a general schema with the main modules of the model. Driving profiles were based on data obtained from travel mobility surveys, and only weekdays were taken into account. For every agent, information for each travel includes: distance, time, average speed and travel cause, either occupational or personal. Travels are then ordered along the day considering its cause and probability functions based on real data.

When the simulation is run, each agent goes about his daily driving profile, and the battery state of charge (SOC) is computed at the end of every travel, considering the distance travelled and the vehicle's consumption rate. Then, the vehicle will be plugged to the network at some time during the day, in order to recharge the batteries. The algorithm chosen for the Li-ion batteries charging is the one proposed in [9], considering a maximum power of 3.7 $\mathrm{kW}$ for all charging events. This rate is thought to become a common option for home-charging, as it is enough to charge completely EV batteries during the night. In this 
model, charging time will be directly dependent on battery size.

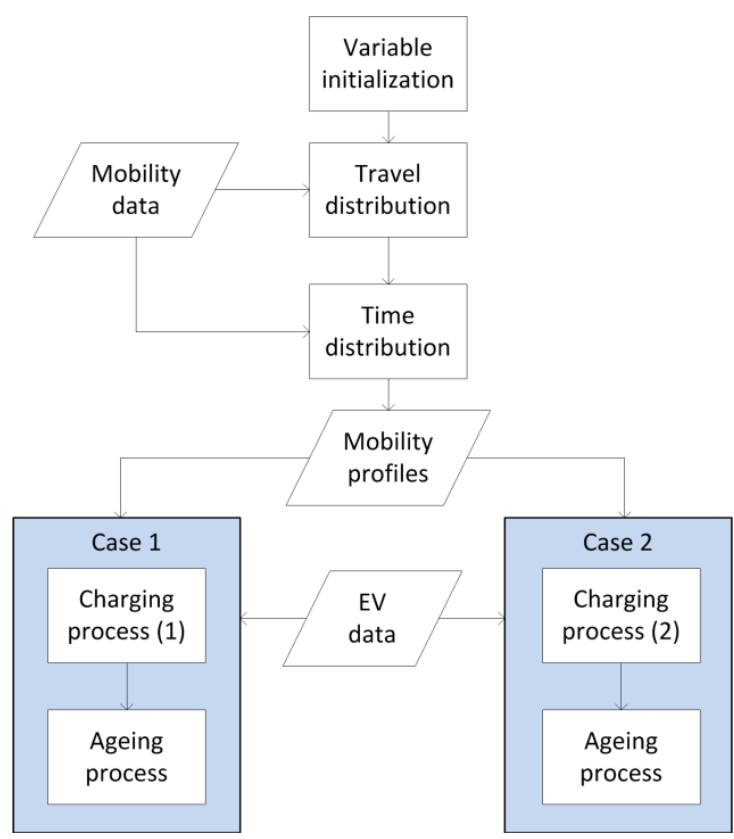

Fig. 1. General model flowchart

Discharging and charging EV batteries involves some kind of battery degradation, hence a storage capacity reduction. The main possible factors which accelerate this capacity fade are discussed in the next section.

\section{Battery ageing model description}

The model for battery ageing used in this study is the one proposed in [10]. It only applies to Li-ion batteries, and is based on theoretical models for crack propagation. Battery specific values are taken from publication [11], where batteries A123 ANR26650M1A are tested under driving conditions. Those are cylindrical lithium iron phosphate batteries intended for PHEV use. The model described shows a good fit with manufacturer data and, at the same time, can be easily adjusted for other Li-ion batteries.

Using the same approach as [12], the model takes into account two different states for the battery during the period. Those are the idle state and the non-idle state. The first one represents the ageing during the time the battery is not being used, therefore, battery degradation will be a function of both battery temperature $(\mathrm{T})$ and time fade $\left(\mathrm{t}_{\text {life }}\right)$, and it is independent of the SOC of the batteries. The second state represents the battery degradation during the time the battery is being cycled, and it will be dependent on time fading, temperature, cycle number $(\mathrm{N})$, average $\mathrm{SOC}\left(\mathrm{SOC}_{\mathrm{avg}}\right)$ and deviation of the SOC $\left(\mathrm{SOC}_{\mathrm{dev}}\right)$.

Equations 1 and 2 correspond to the ageing during the idle state. Temperature related variables are ambient temperature in ${ }^{\circ} \mathrm{K}\left(\mathrm{T}_{\mathrm{a}}\right)$, coefficient of temperature in thermal ageing model $\left(\mathrm{T}_{\text {fact }}\right)$, nominal battery temperature at $25{ }^{\circ} \mathrm{C}\left(\mathrm{T}_{\text {nom }}\right)$ and nominal battery temperature in ${ }^{\circ} \mathrm{K}$ $\left(\mathrm{T}_{\text {nabs }}\right) \cdot \mathrm{t}_{\text {life }}$ stands for the estimated calendar life to $80 \%$ capacity. For the non-idle state, Equations 3 to 6 are used.
Battery specific values stand for coefficient of throughput $\left(\mathrm{K}_{\mathrm{co}}\right)$, exponent constant for depth of discharge $\left(\mathrm{K}_{\mathrm{ex}}\right)$ and coefficient for average state of charge $\left(\mathrm{K}_{\mathrm{soc}}\right)$. $\mathrm{t}_{\text {cycle1 } 1}$ and $t_{\text {cycle2 }}$ stand for time the vehicle has been in each of the states during the period, that is idle and non-idle, respectively.

As Figure 2 shows, the resulting parameters for both states will be added to a single variable $\mathrm{L}$ that ranges from 0 to 1 , as the cell ages from new to having no capacity left at all. It is generally stated that EV batteries come to the end of life (EOL) when only $80 \%$ of the original capacity is left [1] [10] [12] [13], so for this case a value L higher than 0.2 will show the EOL of the battery.

$$
\begin{gathered}
\mathrm{L}_{1}^{\text {idle }}=0.2 \cdot \frac{t_{\text {cycle } 1}}{t_{\text {life }}} \\
\mathrm{L}^{\text {idle }}=L_{1}^{\text {idle }} \cdot \mathrm{e}^{\left(\frac{T_{\text {fact }} \cdot\left(T-T_{\text {nom }}\right) T_{n a b s}}{T_{a}}\right)} \\
\mathrm{L}_{1}^{\text {non-idle }}=0.2 \cdot \frac{t_{\text {cycle } 2}}{t_{\text {life }}} \\
\mathrm{L}_{2}^{\text {non-idle }}=\mathrm{K}_{\text {co }} \cdot \mathrm{N} \cdot \mathrm{e}^{\left(\frac{\text { soc }_{\text {dev }}-1}{\left.K_{\text {ex }} \cdot \frac{T_{\text {nabs }}}{T_{a}}\right)}+\mathrm{L}_{1}^{\text {non-idle }}\right.} \\
\mathrm{L}_{3}^{\text {non-idle }}=\mathrm{L}_{2}^{\text {non-idle }} \cdot \mathrm{e}^{\left(\frac{K_{\text {soc }} \cdot\left(\operatorname{soc} c_{\text {avg }}-0.5\right)}{0.25}\right)} \cdot\left(1-L_{\text {old }}\right) \\
\mathrm{L}^{\text {non-idle }}=L_{3}^{\text {non-idle }} \cdot \mathrm{e}^{\left(\frac{T_{\text {fact }} \cdot\left(T-T_{\text {nom }}\right) \cdot T_{n a b s}}{T_{a}}\right)}
\end{gathered}
$$

With driving profiles computed in the first part of the model, it is possible to obtain the time when the agent is travelling or recharging. This way, at the end of every day the battery degradation is computed for every agent, and added to the overall ageing. Temperature will be the same for all the simulation, and SOC related variables will depend entirely on driving profiles, battery characteristics, and charging conditions defined by the scenario. Capacity fade will actively affect the available capacity for agents, and reduce range along the simulation run.

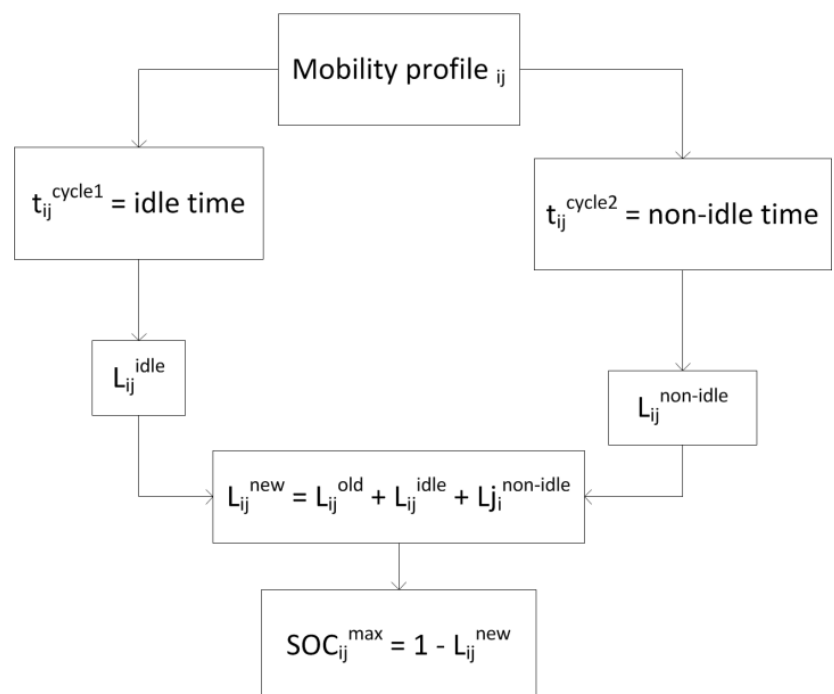

Fig. 2. Ageing flowchart 


\section{Case studies}

Driving profiles have been built using mobility surveys for the city of Barcelona [14] [15]. As explained in previous sections, that will let us represent a broad range of users with different mobility profiles. This mobility survey does not provide specific data for motorcycle users, so users in the simulation that use an EM will have a shorter distance travel for range constraints. The total time simulated will be of 10 years, considering 300 days per year of vehicle use [16]. A temperature of $25^{\circ} \mathrm{C}$ has been set during all the simulation, with a global charging efficiency of $88 \%$ [9] [17].

Two different scenarios have been tested in order to evaluate different charging strategies. In Case 1 , only a single charge at the end of the day is allowed for every car. The objective is to evaluate which percentage of users can go with their daily routines with a single night recharge. In Case 2, recharges in between travels are allowed, in addition to the end of the day recharge, and it is assumed that vehicles will be able to recharge whenever they need it. Furthermore, battery use will be capped to the $80 \%$ of its size, and charging between travels will be triggered when SOC at the arrival is less than $20 \%$. This means that range will be reduced, in respect to users in the first case, but the availability of multiple recharges along the day will diminish the problematic. The limits have been chosen in order to avoid reaching top and bottom battery limits, which represent stressful points of operations.

These charging strategies have been chosen to test how depth of discharge and quantity of cycles affect battery degradation. The first one will imply higher DOD per cycle, whereas in the second case will be lower. Users that cannot end their travels, because they run out of energy, are counted separately as uncompleted travels.

Some assumptions have been taken in order to simplify some aspects of the model that otherwise would have been very difficult to implement, or were simply out of the scope of the study:

- Battery auto discharge has not been taken into account, although it is known to be around $10 \%$ per month [18].

- Regenerative braking has not been considered, because driving profiles are computed using average consumption per kilometre, so acceleration and braking rates are unknown. Nevertheless, it is accounted to represent $5 \%$ of overall battery ageing [1].

- Wave quality elements like harmonics or reactive energy have not been evaluated, although it can produce failures to the grid, when a group of vehicles are recharging in the same one [19].

- All batteries have the same voltage profile, and chemistry, and they only vary in terms of size and consumption.

\section{Results and discussion}

In the following section the different results obtained in each case will be thoroughly discussed and analysed.

\section{Case 1}

The first scenario only contemplated a single recharge every day, so it was expected that batteries would be subject to a high DOD. Figure 3 shows that from the beginning of the simulation, all batteries have suffered a continuous aging. Slightly more than half of the users, in the last day of the simulation, have a battery that has reached its EOL and needs replacement. Batteries $\mathrm{SOH}$ dispersion grow as days pass in the simulation, so users will have different rates of ageing, depending on battery size and vehicle utilization. This is shown in Figure 4, when results for the last day are analysed in detail. It is interesting to note that almost all EVs are above the EOL limit, with values ranging from 80 to $88 \%$ from its initial capacity. On the other hand, almost all PHEVs and EMs are below the EOL mark, with batteries ranging from 74 to $82 \%$. The explanation to this behaviour is that PHEVs and EMs have smaller batteries than EVs. This seems obvious, as PHEVs have an alternative propulsion method and EMs are limited by space and weight. Smaller batteries will have a higher swing, which would affect them negatively, in terms of ageing.

This simulation was also interesting because it can help to test if today's EVs and EMs have enough range to sustain users' everyday needs with a single night recharge at home. From Figure 5 it is possible to say that EVs meet mobility demands, as the percentage of uncompleted trips does not surpass the $2 \%$. In the case of EMs, at the beginning of the simulation $7 \%$ of the travels could not be completed, and the value would grow up till the $12 \%$. This is a consequence of battery ageing, as range and capacity are reduced, but also because these profiles are based on car mobility.

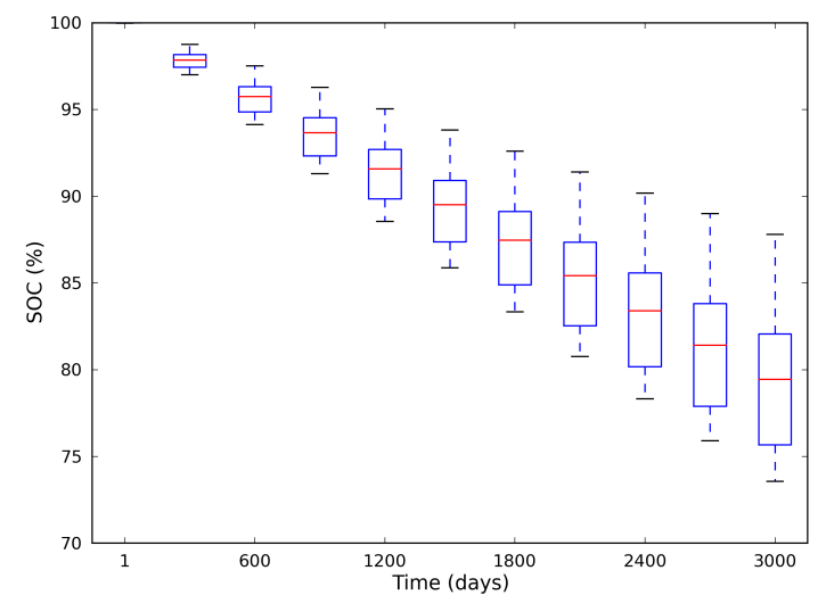

Fig. 3. Battery ageing for Case 1 


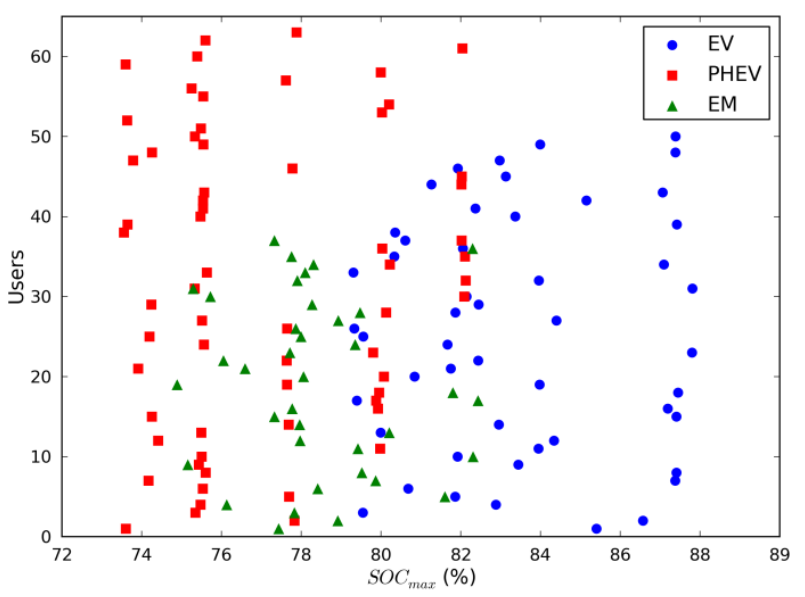

Fig. 4. Battery SOH in the last day of the simulation in Case 1

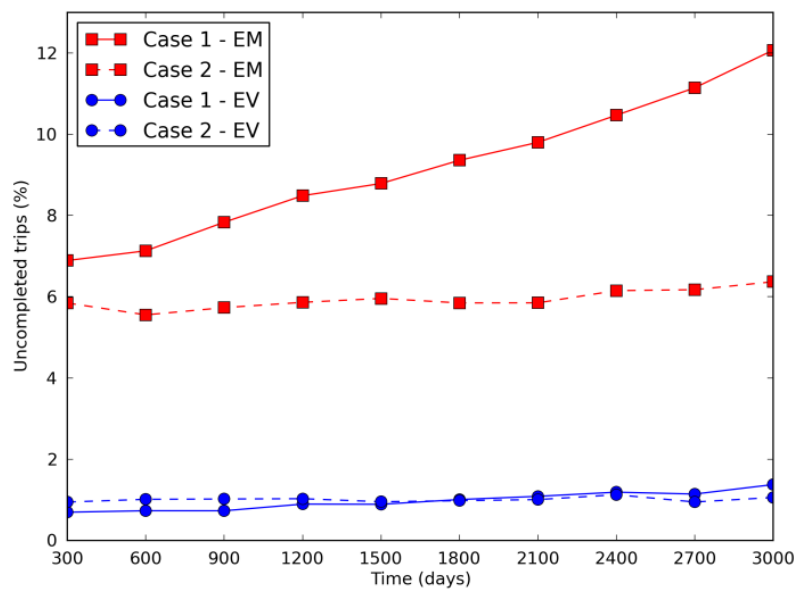

Fig. 5. Percentage of uncompleted travels

Case 2

This case tried to solve high DOD problems showed in the previous case, by reducing the swing limits, and charging between travels. Results for the global ageing showed in Figure 6 demonstrate there has been a positive effect. Battery ageing for EVs and EMs has improved notoriously, and almost all of them have lost less than $20 \%$ of capacity. At the same time, some users have seen their batteries suffer from a higher capacity fade, ending the simulation with only $65 \%$ of initial capacity. Analysing the results for the last day in Figure 7, almost all vehicles have a battery with a better $\mathrm{SOH}$, compared with the previous simulation. Exceptionally, some PHEVs have undergone a higher battery wear. This is explained, again, by knowing that these particular vehicles have a smaller battery. The difference in this case will be that being able to recharge at any moment, and partially emptying the battery in every trip, will cause a higher use with more battery cycles per day.

It has to be noted that in this simulation, a higher amount of energy has been charged in EMs batteries, compared to the previous run. As Figure 5 shows, percentage of uncompleted travels for EMs is reduced to a constant $6 \%$, and the battery degradation does not affect user behaviour. This is explained by the fact that maximum battery charge is capped to $80 \%$ of initial capacity, and in most cases degradation has not yet reached that point, so there will not be a direct impact in terms of range during the simulation period. For EV, rate of uncompleted trips remain similar to the one in Case 1, although during the first 1000 days values are slightly higher because of the battery cap.

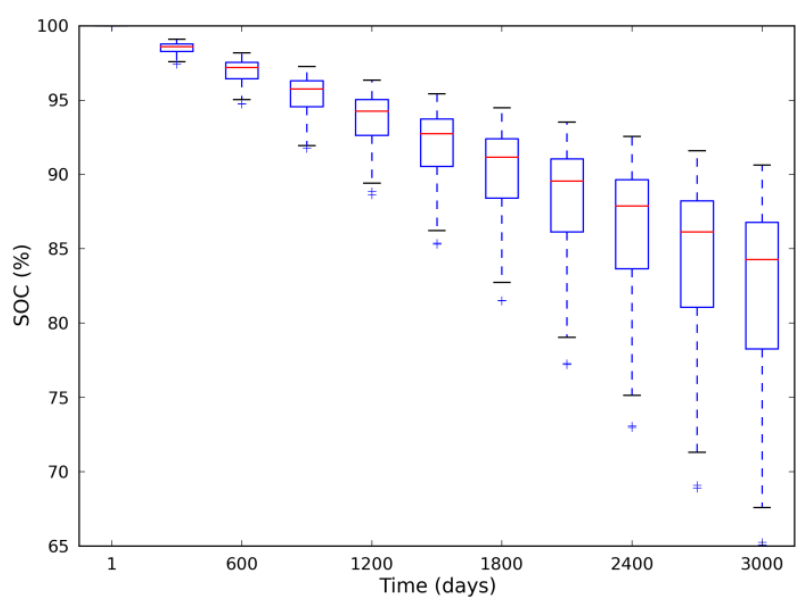

Fig. 6. Battery ageing for Case 2

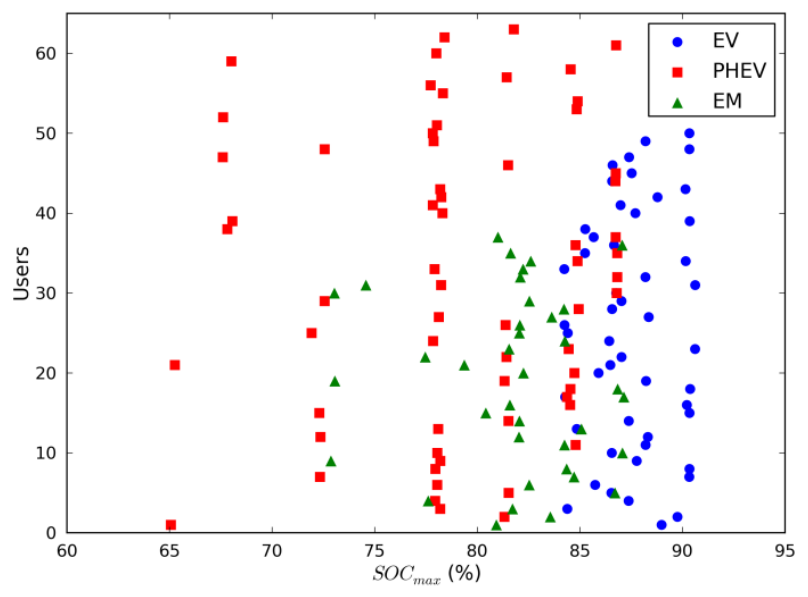

Fig. 7. Battery SOH in the last day of the simulation in Case 2

Finally, after showing effects of ageing under different DOD conditions, it is necessary to observe battery degradation under different temperature conditions. The second case has been rerun for temperatures of 15 and 35 ${ }^{\circ} \mathrm{C}$. The results are shown in Figure 8 where degradation increases proportionally with temperature, having all batteries under the EOL limit for the last day simulated when a temperature of $35^{\circ} \mathrm{C}$ is applied. On the other hand, most of the vehicles have a SOH higher than $90 \%$ with 15 ${ }^{\circ} \mathrm{C}$.

Table 1 shows a summary of both cases at $25{ }^{\circ} \mathrm{C}$. All indicators show an improvement in case 2, in comparison with case 1 . Average non-idle time is slightly similar, although a higher number of daily charging events per user are produced in Case 2. This is because the battery is capped, and the final charging stage is not used for this case, which is slower [9]. Average values of L and percentage of users with less than $80 \%$ capacity left coincides with Figures 4 and 7. 


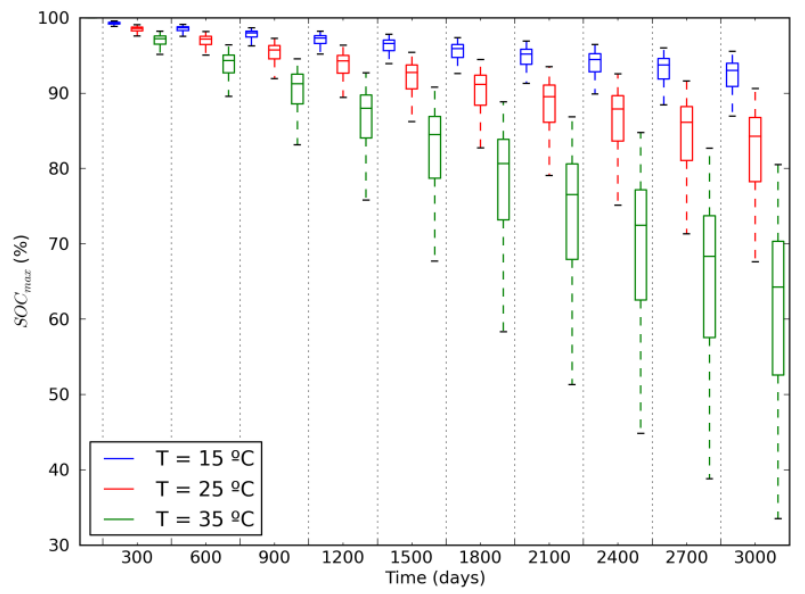

Fig. 8. Comparison of battery ageing at different temperatures in Case 2

\begin{tabular}{|c|c|c|c|c|c|c|}
\hline \multirow{2}{*}{} & \multicolumn{3}{|c}{ Case 1 } & \multicolumn{3}{c|}{ Case 2 } \\
\cline { 2 - 7 } & EV & PHEV & EM & EV & PHEV & EM \\
\hline $\begin{array}{c}\text { Avg. daily } \\
\text { ageing (\%) }\end{array}$ & $\begin{array}{c}5.5 \cdot \\
10^{-3}\end{array}$ & $\begin{array}{c}7.6 \cdot \\
10^{-3}\end{array}$ & $\begin{array}{c}7.2 \cdot \\
10^{-3}\end{array}$ & $\begin{array}{c}4.1 \cdot \\
10^{-3}\end{array}$ & $\begin{array}{c}6.9 \cdot \\
10^{-3}\end{array}$ & $\begin{array}{c}6.0 \\
10^{-3}\end{array}$ \\
\hline Avg. L (\%) & 16.5 & 22.9 & 21.6 & 12.3 & 20.9 & 18.1 \\
\hline $\begin{array}{c}\text { Avg. non- } \\
\text { idle time (h) }\end{array}$ & 19.6 & 19.4 & 21.3 & 19.6 & 19.0 & 21.0 \\
\hline C < 80\% & $12 \%$ & $80 \%$ & $83 \%$ & $0 \%$ & $55 \%$ & $19 \%$ \\
\hline $\begin{array}{c}\text { Charging } \\
\text { events }\end{array}$ & 1 & 1 & 1 & 1 & 1.3 & 1.2 \\
\hline
\end{tabular}

\section{Conclusions}

The model presented in this study successfully represents battery degradation as a consequence of temperature and vehicle utilisation. The two cases evaluated have demonstrated different rates of battery wear depending on the way the battery is charged and discharged, thus how DOD affects capacity fade. Some interesting results for PHEVs have been observed in the second case, as the ones with smaller batteries had a worse ageing than the others. At the same time, for case 2, percentage of users with a battery not in the EOL state has improved largely, in relation with case 1 . Furthermore, a relation between capacity reduction and uncompleted travels has been demonstrated. Finally, the same scenario under different temperature conditions has been studied, concluding that a higher temperature involves a higher degradation.

Further work would involve working with a real life battery, which can validate the model. In addition, a vehicle to grid module could be developed, to test how this extra activity could affect battery ageing, and add economic implications.

\section{References}

[1] G. Duleep, H. v. Essen, B. Kampman and M. Grünig, "Impacts of Electric Vehicles - Deliverable 2. Assessment of electric vehicles and battery technology," CE Delft, 2011.

[2] International Energy Agency (IEA), “Global EV Outlook. Understanding the Electric Vehicle Landscape 2020," 2013.

[3] K. Smith, M. Earleywine, E. Wood, J. Neubauer and A. Pesaran, "Comparison of Plug-In Hybrid Electric Vehicle Battery Life Across Geographies and Drive Cycles," SAE Technical Paper, 2012.

[4] E. Wood, J. Neubauer, A. D. Brooker, J. Gonder and K. A. Smith, Variability of Battery Wear in Light Duty Plug-in Electric Vehicles Subject to Ambient Temperatures, Battery Size and Consumer Usage, National Renewable Energy Laboratory (NREL), 2012.

[5] P. Olivella, Modelado de la demanda de carga lenta y rápida de vehículos para el estudio de impacto en la red de distribución, Escola Tècnica Superior d'Enginyeria Industrial de Barcelona (UPC), 2012.

[6] C. Macal and M. North, "Tutorial on agent-based modelling and simulation," Journal of Simulation, vol. 4, pp. 151-162, 2010.

[7] E. Bonabeau, "Agent-based modeling: Methods and techniques for simulating human systems,"

Proceedings of the National Academy of Sciences of the United States of America, vol. 99, pp. 7280-7287, 2002.

[8] E. ElBanhawy, R. Dalton, E. M. Thompson and R. Kotter, "A Heuristic Apporach for Investigating the Integration of Electric Mobility Charging Infrastructure in Metropolitan," in 2nd International symposium on Environment Friendly Energies and Applications, 2012.

[9] F. Marra, Guang Ya Yang, C. Traholt, E. Larsen, C. Rasmussen and Shi You, "Demand profile study of battery electric vehicle under different," Power and Energy Society General Meeting, pp. 1-7, 2012.

[10] A. Millner, "Modeling Lithium Ion Battery Degradation in Electric," in Innovative Technologies for an Efficient and Reliable Electricity Supply (CITRES), 2010.

[11] S. B. Peterson, J. Apt and J. F. Whitacre, "Lithiumion battery cell degradation resulting from realistic vehicle and vehicle-to-grid utilization," Journal of Power Sources, vol. 195, pp. 2385-2392, 2010.

[12] S. Karagiannopoulos, Battery modeling within Plugin Vehicle Fleet Simulations in Smart-Grids, EEH Power Systems Laboratory, ETH Zurich, 2012.

[13] A. Dinger, R. Martin, X. Mosquet, M. Rabl, D. Rizoulis, M. Russo and G. Sticher, Batteries for Electric Cars. Challenges, Opportunities, and the Outlook to 2020, The Boston Consulting Group, 2010.

[14] Autoritat del Transport Metropolità (ATM), “Enquesta Mobilitat Quotidiana 2006," 2006. 
[15] Institut d'Estudis Regionals i Metropolitans de Barcelona (IERMB), Enquesta de Mobilitat en dia Feiner (EMEF), 2012.

[16] J. Pallisé, F. Astals, I. Cair, J. Comellas, F. Martínez and J. Serra, "Diagnosi i perspectives del vehicle elèctric a Catalunya - (Informes del CADS ; 10)," Consell Assessor per al Desenvolupament Sostenible (CADS), 2010.

[17] K. Clement-Nyns, E. Haesen and J. Driesen, "The Impact of Charging Plug-In Hybrid Electric Vehicles on a Residential Distribution Grid," Power Systems, pp. 371-380, 2010.

[18] I. Buchmann, Batteries in a Portable World: A Handbook on Rechargeable Batteries for NonEngineers, Cadex Electronics Inc, 2001.

[19] E.Valsera-Naranjo, A. Sumper, A.; R. VillafafilaRobles, D. Martínez-Vicente, Probabilistic Method to Assess the Impact of Charging of Electric Vehicles on Distribution Grids. Energies 2012, 5, 1503-1531. 